\title{
Erratum to: Use of a SPAD-502 meter to measure leaf chlorophyll concentration in Arabidopsis thaliana
}

\author{
Qihua Ling • Weihua Huang • Paul Jarvis
}

Published online: 30 March 2011

(C) Springer Science+Business Media B.V. 2011

\section{Erratum to: Photosynth Res (2011) 107:209-214 \\ DOI 10.1007/s11120-010-9606-0}

Due to the omission of a scaling factor of 4 from the chlorophyll per leaf area calculations, all values with units of $\mathrm{nmol} / \mathrm{cm}^{2}$ were fourfold higher than they should have been. This affected the y-axis values in Figs. 1b, 2b, 3b (left side) and $4 \mathrm{~b}$ (left side); the maximal $\mathrm{y}$-axis values should be 30, 25, 15 and 35, respectively. Most importantly, the equation in Fig. 1b should be:

$\mathrm{y}=0.0105 \mathrm{x}^{2}+0.4119 \mathrm{x}+0.3810$.

None of the chlorophyll per fresh weight data are affected by this erratum, nor is the running text influenced in any way. All $R^{2}$ values are unaffected.

The online version of the original article can be found under doi: 10.1007/s11120-010-9606-0.

Q. Ling $\cdot$ W. Huang $\cdot$ P. Jarvis $(\bowtie)$

Department of Biology, University of Leicester,

University Road, Leicester LE1 7RH, United Kingdom

e-mail: rpj3@le.ac.uk

Present Address:

W. Huang

Institute of Plant Physiology and Ecology, Shanghai Institutes

for Biological Sciences, Chinese Academy of Sciences,

300 Fenglin Road, Shanghai 200032, China 